\title{
O Atlas Geográfico Municipal como Recurso Didático no Ensino de Geografia: elaboração e perspectivas formativas
}

\author{
The Municipal Geographic Atlas as a Didactic Resource in Geography Education: \\ elaboration and prospects for training
}

\section{El Atlas Geográfico Municipal como Recurso Didáctico en Enseñanza de Geografía: perspectivas de preparación y entrenamiento}

\author{
Karen Laiz Romig ${ }^{1}$
}

Sandro de Castro Pitano ${ }^{2}$

\begin{abstract}
RESUMO: O artigo apresenta um estudo sobre a elaboração e o uso do atlas geográfico escolar municipal, segundo a concepção docente, no processo de ensino e aprendizagem da Geografia no Ensino Fundamental. Expõe resultados de uma pesquisa meta-analítica que explicitou diferentes processos e resultados de projetos que elaboraram atlas municipais de diferentes municípios brasileiros. A realidade desses projetos foi relacionada com a de um município que não dispõe desse recurso na rede de ensino, como é o caso de Canguçu-RS, apontando diferentes formas e possibilidades do público escolar (professores e alunos) usar o atlas municipal como ferramenta pedagógica do estudo do local. Para isso, analisaram-se cinco diferentes concepções de atlas municipais e foram desenvolvidas entrevistas semiestruturadas com professoras do Ensino Fundamental no município de Canguçu-RS. Nas conclusões, salienta-se a relevância desse recurso nas aulas de Geografia, sobretudo pela base local do conteúdo, familiar aos alunos, além de destacar a pertinência dos processos de elaboração e das abordagens didáticas que permeiam os cinco exemplos analisados. $O$ artigo destaca que seria importante a elaboração participativa do atlas municipal como perspectiva de formação continuada para professores e professoras, além de representar uma qualificada alternativa didática para o ensino de Geografia no município.
\end{abstract}

PALAVRAS-CHAVE: Atlas geográfico escolar. Geografia. Ensino Fundamental. Recursos didáticos. Escola.

\begin{abstract}
The article presents a study about the elaboration and the use of the municipal school geographic atlas, according to the teaching conception, in the teaching and learning process of the Geography in the Elementary School. It presents results of a meta-analytical research that explained different processes and results of projects that elaborated municipal atlases of different Brazilian municipalities. In which the reality of these projects was related to the reality of a municipality that does not have this resource in the school system, as in the municipality of Canguçu-RS, pointing out different ways and possibilities of the school public (teachers and students) to use the municipal atlas as pedagogical tool for site study. For this, five different conceptions of municipal atlases were

\footnotetext{
1 Universidade Federal de Pelotas. R. Gomes Carneiro, 1 - Centro, Pelotas - RS, 96010-610. karenlaizromig@gmail.com.

${ }^{2}$ Universidade Federal de Pelotas. R. Gomes Carneiro, 1 - Centro, Pelotas - RS, 96010-610. scpitano@gmail.com.
} 
analyzed and semi-structured interviews were conducted with elementary school teachers in the municipality of Canguçu-RS. In the conclusions, the relevance of this resource in Geography classes is emphasized, especially by the local content base, familiar to the students, besides highlighting the relevance of the elaboration processes and didactic approaches that permeate the five analyzed examples. The article highlights that the participatory elaboration of the municipal atlas would be important as a perspective of continuing education for teachers, besides representing a qualified didactic alternative for the teaching of geography in the municipality.

KEYWORDS: School geographic atlas. Geography. Elementary school. Didactic resources. School.

RESUMEN: El artículo presenta un estudio sobre la elaboración y el uso del atlas geográfico de la escuela municipal, según la concepción docente, en el proceso de enseñanza y aprendizaje de la Geografía en la Escuela Primaria. Presenta los resultados de una investigación metaanalítica que explicó diferentes procesos y resultados de proyectos que elaboraron atlas municipales de diferentes municipios brasileños. En el cual la realidad de estos proyectos estuvo relacionada con la realidad de un municipio que no cuenta con este recurso en el sistema escolar, como en la ciudad de Canguçu$R S$, señalando diferentes formas y posibilidades del público escolar (docentes y alumnos) de utilizar el atlas municipal como Herramienta pedagógica para el estudio del sitio. Para esto, se analizaron cinco concepciones diferentes de atlas municipales y se realizaron entrevistas semiestructuradas con maestros de primaria en el municipio de Canguçu-RS. En las conclusiones, se destaca la relevancia de este recurso en las clases de Geografía, especialmente por la base de contenido local, familiar para los estudiantes, además de resaltar la relevancia de los procesos de elaboración y los enfoques didácticos que impregnan los cinco ejemplos analizados. El artículo destaca que la elaboración participativa del atlas municipal sería importante como una perspectiva de educación continua para los docentes, además de representar una alternativa didáctica calificada para la enseñanza de la geografía en el municipio.

PALABRAS-CLAVE: Atlas geográfico escolar. Geografía. Enseñanza fundamental. Recursos didácticos. Escuela.

\section{INTRODUÇÃO}

O presente estudo, situado na área do ensino de Geografia, traz como perspectiva o atlas geográfico escolar municipal como recurso didático no processo formativo. Propõe, como objetivo principal, relacionar processos de elaboração de atlas municipais com a realidade de um município que não possui esse recurso, apontando diferentes formas e contextos do uso da ferramenta do atlas municipal nas escolas. Relaciona o uso do atlas com o estudo do município, apontando soluções para a deficiência que existe com relação às formas de trabalhar os aspectos geográficos dos espaços locais no nível de Ensino Fundamental da educação básica.

O desenvolvimento do ensino de Geografia por meio do uso de métodos e recursos didáticos permite que os alunos tenham um maior interesse pela disciplina, pois desta forma ela se insere mais significativamente em suas realidades locais. Caracteriza-se o atlas como um recurso potencialmente atrativo, reunindo elementos basilares e capazes de contribuir amplamente para uma adequada iniciação cartográfica dos alunos no Ensino Fundamental. Seja nos anos iniciais ( $1^{\circ}$ ao $5^{\circ}$ ), quando as crianças entre 7 e 11 anos estabelecem os 
primeiros contatos com a cartografia escolar, ou nos anos finais ( $6^{\circ}$ ao $9^{\circ}$ ), em meio às habilidades exigidas na continuidade da escolarização.

O atlas geográfico tem como proposta não ser apenas uma coletânea de mapas prontos e acabados, mas sim compor uma organização sistemática de informações e representações, trabalhadas com finalidade intelectual específica (MARTINELLI, 2008). É uma importante ferramenta que possibilita a compreensão do conteúdo de maneira mais clara, objetiva e dinâmica, sendo uma forma interativa de inserir os alunos na linguagem cartográfica. Permite que conheçam melhor o espaço imediato e consigam estabelecer relações entre o seu cotidiano e os contextos mais distantes, considerados globais. Pode ser utilizado para a localização e análise de cidades e para a compreensão de elementos físicos, econômicos, políticos, populacionais, ambientais ou naturais, entre outros, de maneira crítica e dinâmica.

O município de Canguçu abrigou a dimensão empírica da pesquisa, composta por entrevistas do tipo semiestruturado com professoras que atuam no Ensino Fundamental. Nessa fase, a pesquisa procurou destacar alguns aspectos da realidade do ensino no município, bem como identificar as metodologias que cada professora adota em relação ao contexto mais amplo de sua prática, enfatizando o uso do atlas geográfico. Canguçu é um município localizado no sul do Estado do Rio Grande do Sul, com uma população de aproximadamente 56 mil habitantes (Figura 1). De acordo com o IBGE (2010) 63\% da sua população vive no campo, o que em números significa cerca de 33.400 pessoas pertencentes à zona rural.

Esta pesquisa é definida como um estudo exploratório com base em Gil (2002). Envolveu também análise bibliográfica, utilizando fontes como Aguiar (2003), Almeida (2003) e Martinelli (2008), referenciais que se destacam na concretização de estudos relacionados ao tema.

Também foram analisados artigos publicados em periódicos científicos, dissertações de mestrado e teses de doutorado que se ocuparam da construção de atlas e protótipos de atlas de outros municípios do Brasil. Foram utilizados sites como o do IBGE para a obtenção de dados específicos demandados pela pesquisa. Esses materiais serviram de aporte teórico e técnico para a revisão bibliográfica sobre a elaboração e o uso do atlas no ensino de Geografia para o nível fundamental.

O referencial teórico utiliza autores como Bueno (2008), Cirolini (2014), Faria (2015) Lima (2013), e Machado-Hess (2012b), que trabalham com a temática de atlas escolares, ou com experiências na elaboração de atlas municipais. Inicialmente procedeu-se este estudo bibliográfico, na forma de uma meta-análise, para posteriormente desenvolver uma comparação entre essas experiências e a realidade de usos de atlas geográficos, projetando a possível elaboração de um atlas municipal do município de Canguçu. 
Figura1 - Mapa da localização do município de Canguçu

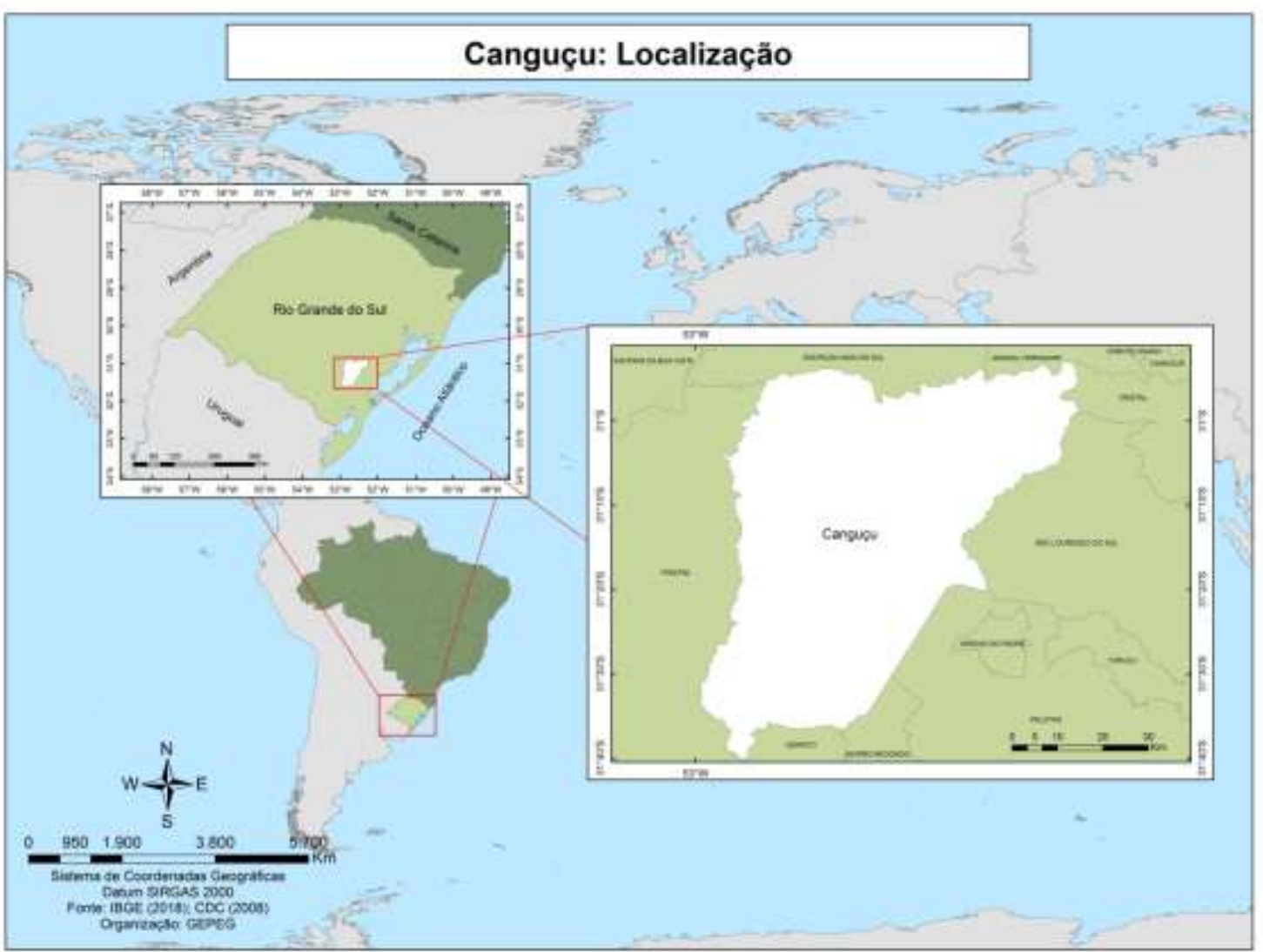

Fonte: IBGE (2018).

Outro procedimento metodológico que caracteriza este artigo é a pesquisa de levantamento, promovendo consulta direta a pessoas que se envolvem no processo de ensino e aprendizagem da Geografia. Procedeu-se à solicitação de informações junto a um grupo significativo de professores que atuam na rede básica de ensino sobre o problema estudado para, em seguida, mediante análise quantitativa, obterem-se as conclusões correspondentes aos dados coletados, conhecendo assim a realidade estudada. Nesta pesquisa os professores são questionados, possibilitando que um quadro de informações e parâmetros referentes ao uso do atlas no município de Canguçu fosse elaborado.

Foram realizadas entrevistas semiestruturadas com professoras da rede municipal de Canguçu-RS que lecionam Geografia para o Ensino Fundamental. Optou-se por enfocar o $4^{\circ}$ e $05^{\circ}$ anos, devido ao conteúdo programático englobar, sobretudo, os aspectos geográficos do município. Foram entrevistadas oito professoras, as quais relataram a concepção sobre o papel do atlas no ensino da Geografia, com ênfase no enfrentamento didático dos estudos sobre o espaço local, representado pelo município. Por meio das entrevistas foi possível conhecer de forma sintética e geral a realidade escolar vivenciada 
por essa parcela de professoras, verificando diferentes concepções quanto ao uso e a importância didática atribuída ao atlas geográfico.

A explanação deste artigo salienta inicialmente a relevância do uso do atlas geográfico nas aulas de Geografia, sobretudo pelo estudo do local onde os estudantes se inserem, demonstrando a pertinência dos processos de elaboração e das abordagens didáticas que permeiam os cinco exemplos que serão analisados. O texto também destaca a elaboração participativa do atlas municipal como perspectiva de formação continuada para professores e professoras, além de representar uma qualificada alternativa didática para o ensino de Geografia no município de Canguçu - RS.

\section{O ATLAS COMO RECURSO DIDÁTICO}

Considerando o público ao qual se destina o atlas, Lima (2013, p. 7) afirma que "[...] o objetivo principal do atlas escolar municipal é promover a identidade e o pertencimento através do conhecimento sobre o lugar". O atlas escolar geográfico tem como finalidade revelar aos alunos conhecimentos amplos e específicos de determinado local, principalmente do seu espaço vivencial imediato. Ele traz em seu contexto mapas, ilustrações, informações e dados em geral, cujo conteúdo tem uma finalidade específica, que varia de acordo com quem está consultando e os objetivos da ação.

$\mathrm{O}$ atlas pode ser considerado como um recurso didático que proporciona aos alunos e professores, quando utilizado na escola, uma interação entre elementos como os mapas, as imagens e os textos, que conversam entre si. Como destacam Martinelli e Ferreira (1995) o mapa é a representação gráfica reduzida e seletiva dos espaços, a fotografia pode melhor expor os conceitos geográficos e o texto constitui uma legenda explicativa das fotografias e dos mapas.

O atlas escolar municipal é um recurso que permite pensar o espaço geográfico como a mediação entre o mundo e o lugar. O ensino do lugar nas séries iniciais do ensino fundamental refere-se à possibilidade de fazer com que os alunos aprendam a habitar o seu lugar. É estudando os mapas da sua cidade que os alunos podem apropriar-se de um instrumento de exploração e melhor conhecimento de territórios existenciais e cognitivos que permitem dar visibilidade ao mundo (AGUIAR, 2003).

O atlas municipal é composto por mapas, imagens, gráficos, tabelas e conteúdos escritos que se referem à história, população, economia, características físicas e paisagens de determinado município. Isso tende (ainda que não garanta) a promover um ensino interativo e uma aprendizagem dinâmica, na qual o aluno tem a possibilidade de ler o espaço empiricamente vivenciado, observá-lo e melhor entendê-lo. 
O atlas geográfico comumente utilizado nas escolas propicia aos alunos 0 aprofundamento do conhecimento sobre o seu contexto empírico cotidiano, por meio da abstração crítica em relação ao lugar de pertencimento. Como afirma Martinelli (2008, p. 24), nesse contexto "[...] os mapas não seriam vistos como tradicionalmente se faz, como meras figuras ilustrativas dos textos didáticos" e sim como "[...] representações reveladoras de questões que serão abordadas e discutidas nos discursos geográficos, dando chance a uma reflexão crítica e consciente". Para isso são necessárias intervenções para que os possíveis usuários deste atlas percebam a importância do uso dos mapas e também saibam interpretar os mesmos, ou seja, em que os alunos possam ler os mapas, e não simplesmente os olhar sem entender.

Por sua vez, Almeida (2003) ressalta que o atlas geográfico escolar municipal compõe um subsídio fundamental para a realização de atividades didáticas em sala de aula, utilizando informações e dados atualizados.

O atlas é considerado também um auxílio para a iniciação cartográfica, ou seja, fundamenta os primeiros contatos da criança com o conhecimento geográfico por meio de suas formas de representação.

Para Machado-Hess (2012b, p. 222), “[...] os atlas escolares, como qualquer outro recurso didático, devem respeitar a idade mental da criança, e assim, apresentar um conteúdo diversificado". Organizados de forma apropriada, podem ser aproveitados e explorados nos diferentes anos do Ensino Fundamental. Os mapas e demais informações contidas no atlas devem ser redigidas de forma simples, para que os alunos compreendam o conteúdo necessário em relação ao planejado pelos professores. Conteúdos inapropriados à idade/série, ou de abrangência muito complexa, provocam conflitos múltiplos no processo de ensino e aprendizagem, inclusive o antagonismo entre alunos e disciplinas.

O atlas como ferramenta de auxílio para professores de Geografia pode abordar, além do contexto municipal, a representação do planeta, do país e de seus respectivos estados, o que permite o desenvolvimento de concepções de escala e atividades de comparação espacial, extrapolando a incidência e a pertinência pedagógica sobre um ou mais de um ano específico na educação escolar.

Os atlas apresentados atualmente são complexos, contendo dados cada vez mais enriquecidos por uma infinidade de ferramentas, possibilitando a inserção de informações claras e rapidamente compreensíveis. Destaca-se o uso de imagens, gráficos, tabelas e croquis, entre outros. Isto representa um intenso processo de evolução da Geografia escolar no decorrer dos tempos (FRANÇA JUNIOR; ZUCCHI, 2013). De acordo com Lima (2013, p. 25), 
Quando falamos de atlas escolares elaborados e concebidos para as crianças, esta importância torna-se ainda maior, visto que elas se tornarão os futuros leitores conscientes do seu mundo. Esta tarefa é tão fundamental que no porvir as pessoas não irão mais necessitar de emprestar os olhos do outro para entender o local onde vivem e o resto do mundo que os rodeia, seus próprios olhos serão capazes de "decifrar" e compreender todos os códigos e transformações permeadas de conflitos e ideologias impostas pela sociedade capitalista.

Os atlas municipais podem ser considerados recursos inovadores, se existentes e bem construídos, diante das tantas lacunas didáticas existentes nas escolas. Motivam os docentes e discentes a relacionar as representações espaciais, dinamizando o estudo do espaço vivido, mesmo que este recurso não seja perfeito, mas outra ferramenta de auxílio para o professor. Essa realidade exige que os processos de sua elaboração sejam permanentemente qualificados e atualizados em termos pedagógicos e tecnológicos. Também revela o quanto é necessário aferir a eficiência didática destes atlas em meio ao processo concreto de ensino e aprendizagem no Ensino Fundamental (CIROLINI, 2014). É possível perceber que a elaboração do atlas municipal tem investido na apropriação de ferramentas digitais atualizadas, resultando em conteúdos e meios variados à disposição dos sujeitos (professores e alunos). A ferramenta do atlas municipal pode também contribuir em outras discussões dentro da escola, não somente da Geografia, mas também em questões sociológicas e históricas.

Outra via importante para a qualificação do ensino e da aprendizagem da Geografia é a formação continuada dos professores que atuam no nível fundamental, sobretudo aqueles e aquelas que não possuem formação inicial nessa área, promovendo um debate formativo mais abrangente sobre o trabalho pedagógico com elementos locais. Ou seja, para além da formação obtida na graduação, permite que os profissionais possam dimensionar e compreender melhor as necessidades dos alunos, possibilitando que eles se encontrem e se localizem nos mapas, apropriando-se do conhecimento geográfico por meio das muitas formas de representação espacial disponíveis, as quais são, não raro, desconhecidas pelos professores.

A precariedade na formação inicial e continuada é percebida nas entrevistas semiestruturadas com professoras de Canguçu. Muitas desconhecem a possibilidade de trabalhar com a temática do município e também a utilização de materiais didáticos que tratem do local de vivência do aluno, o que demanda a formação continuada ou participação em oficinas didáticas que trabalhem com a temática. $O$ ensino de Geografia acaba por se deter para fora das bases locais, isto é, para outras realidades que não são as dos alunos envolvidos no processo de ensino-aprendizagem. 
A elaboração de um atlas geográfico escolar municipal prevê o estabelecimento de parceria entre as pessoas e os recursos disponíveis, a aceitação dos desafios impostos e o enfrentamento das necessidades, tanto previstas como não previstas. Com as entrevistas que tematizaram o cenário atual do ensino de Geografia no município de Canguçu-RS, percebe-se que $o$ atlas representaria uma alternativa concreta e promissora para que os alunos se identifiquem com o local onde vivem, atrelando, portanto, pertencimento e aprendizagem qualificada em meio à ação educativa no ambiente escolar.

\section{A ELABORAÇÃO DE ATLAS ESCOLARES MUNICIPAIS}

Tendo analisado o processo de elaboração de alguns atlas escolares, cabe salientar, de maneira breve, quais as principais metodologias empregadas e os respectivos enfoques temáticos, permitindo que sejam compreendidos e, eventualmente, utilizados em projetos futuros com semelhante finalidade.

É almejada a reunião de elementos capazes de serem apropriados construtivamente, em conjunto com o resultado das entrevistas, no sentido de delinear uma tipologia de atlas adequada ao contexto escolar atual, assim como relacionar os processos de elaboração de atlas municipais com a realidade de um município específico, como Canguçu. O estudo compreendeu cinco propostas, as quais serão expostas a seguir: Atlas Municipal de Sumaré - SP, Atlas Municipal de Apucarana - PR, Atlas Municipal de Sorocaba - SP, Atlas Municipal de Restinga Sêca - RS e Atlas Municipal de Sena Madureira - AC.

\section{Atlas Municipal de Sumaré - SP}

Um dos principais objetivos deste projeto paulista foi construir um material didático que promovesse um sentimento de pertencimento ao município de Sumaré. O Atlas de Sumaré foi elaborado com destaque para as referências culturais dos alunos. Foi desenvolvida uma pesquisa para fazer o diagnóstico das principais referências culturais dos discentes do município em questão. Tutoras do projeto realizaram vários registros das práticas escolares nas suas escolas, sobre o ensino da cidade e do bairro onde a escola está localizada. $A$ partir destes registros, foram feitas análises e definidos eixos temáticos. A seguir é apresentada uma imagem que demonstra a capa deste atlas (Figura 2).

$\mathrm{Na}$ capa há uma interação entre elementos geográficos que fazem menção ao município representado, como uma imagem aérea da cidade, dentro dos limites territoriais do município de Sumaré.

A coleta de dados do projeto aconteceu no ano de 2006 . Foram sorteados $10 \%$ dos alunos com distribuição igual por sexo, idade/série e os bairros onde moravam para a 
realização de entrevistas. Como explica Lima (2013), foram levantados dados e indicadores de condições familiares, como origem, tempo de moradia em Sumaré, profissão e grau de instrução dos pais; relação do aluno com o lugar onde mora: trajeto que faz para a escola, lugares que frequenta e que conhece, o que sabe sobre Sumaré e sua importância; referências culturais: atividades de lazer, esporte, religião, festas que frequenta, brincadeiras e músicas que prefere.

Figura 2 - Capa do Atlas de Sumaré

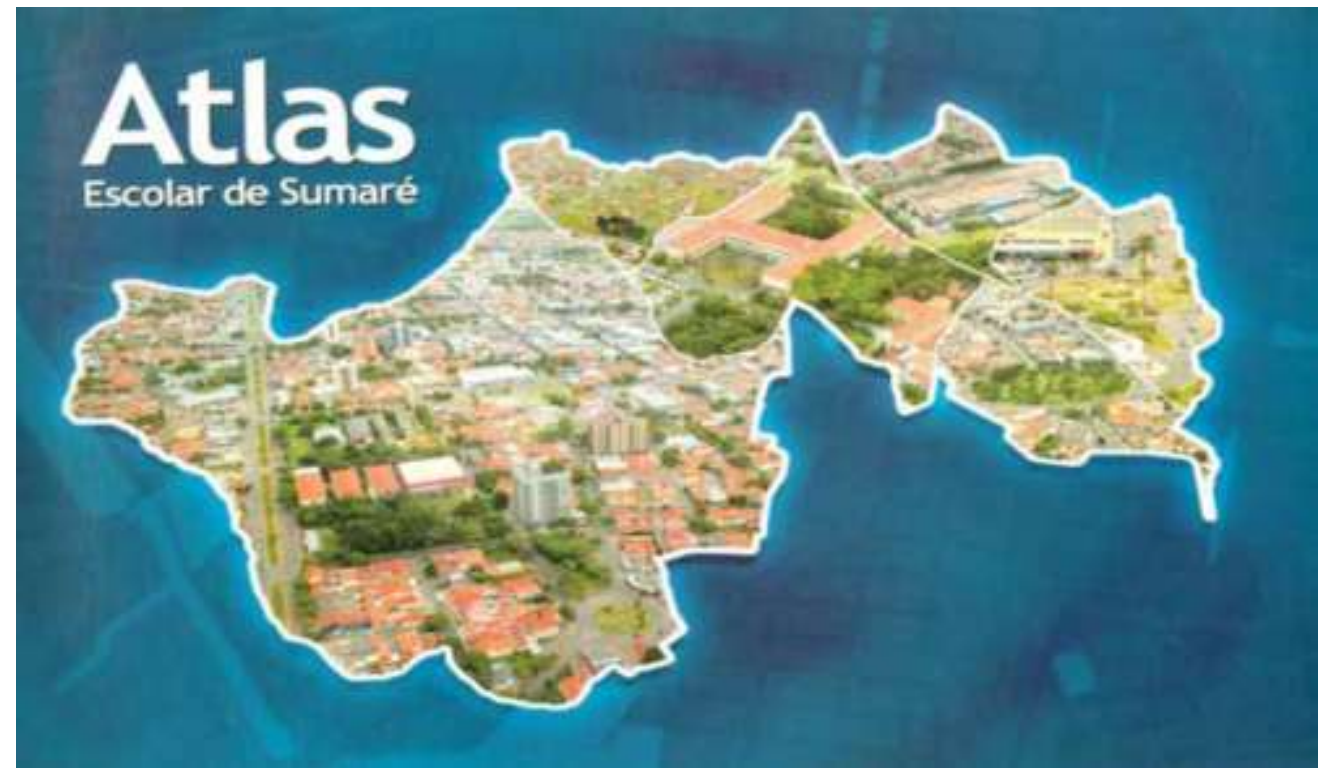

Fonte: Lima (2013).

Com a obtenção destes dados foi possível estabelecer os principais eixos para os temas que foram apresentados no Atlas Municipal de Sumaré. As tiragens iniciais foram de sete mil exemplares, sendo que os atlas foram distribuídos em todas as escolas municipais, também possibilitando a consulta pelas escolas estaduais.

Além do lançamento do atlas na versão impressa, foram elaborados também três DVDs (Sumaré.doc), que contemplam os eixos: Cidade e Natureza; Estado e Cidadania; Identidade e Pertencimento; Trabalho e Consumo, divididos em dez vídeos aulas.

O eixo Cidade e Natureza abordou temas como a natureza se transformando no tempo e no espaço, e as subdivisões dentro deste eixo são: sítios arqueológicos; os caminhos que formaram o território paulista; caminhos dos bandeirantes; origem de Sumaré; a cidade orquídea; a região do quilombo; relevo; o crescimento da cidade e a transformação da natureza.

O eixo Estado e Cidadania considera temas como os movimentos migratórios, a ocupação do espaço, a imigração: migração e indústrias; e indústrias e loteamentos. Já o eixo Identidade e Pertencimento aborda as questões de vínculo com a área analisada, e o pertencimento ao município de Sumaré. E por último, o eixo Trabalho e Consumo trata das 
indústrias em Sumaré, da rede viária, dos serviços de saúde e educação, além da questão aquática e de saneamento básico.

\section{Atlas Municipal de Apucarana - PR}

O Atlas Municipal e Escolar Geográfico, Histórico, Ambiental de Rio Claro foi o que serviu de modelo para a elaboração do protótipo do Atlas de Apucarana. O protótipo do Atlas de Apucarana continha 74 páginas e foi organizado com fotos, imagens, figuras, textos e mapas.

De acordo com Faria (2015) foram reunidos os seguintes materiais cartográficos já existentes: mapa de uso e ocupação do solo, na escala de 1:1000, cedido pela Prefeitura Municipal de Apucarana; Planta Parcial da Cidade de Apucarana - CTNP (Companhia de Terras Norte do Paraná), na escala de 1:5000, cedida também pela prefeitura; mapa das Mesorregiões Geográficas, na escala de 1:100:000, disponibilizado no site do governo estadual do Paraná.

Outro ponto bastante significativo da pesquisa de Apucarana foi a revisão bibliográfica para a obtenção de dados históricos e geográficos do município. Foram coletadas fotos históricas e imagens em sites como o da Prefeitura Municipal, além de visitas ao Museu Histórico de Apucarana.

O programa utilizado para a elaboração dos mapas foi Corel Draw X6. A elaboração do protótipo do Atlas de Apucarana procurou evidenciar os diferentes momentos ocorridos na história do município, e os elementos geográficos e ambientais. O protótipo foi organizado em quatro grandes temas principais, que são: Aspectos Cartográficos, Nossa História, Geografia, e Meio Ambiente, que posteriormente foram subdivididos em subtemas. Os temas do Atlas de Apucarana foram organizados em seções e tiveram como títulos: Aspectos Históricos, Aspectos Geográficos, Aspectos Ambientais, Aspectos Cartográficos e Geográficos e Símbolos Oficiais.

Conforme explica Faria (2015, p. 103), "O tamanho das páginas, foram de dimensão A4, com impressão colorida. Os temas foram representados em páginas formando duplas, sendo que os textos, imagens ou fotos apresentaram-se na página esquerda, já os mapas na página direita".

A partir da elaboração do protótipo seguiu-se para a concretização do Atlas de Apucarana, com base em uma pesquisa colaborativa, na qual a comunidade pode se integrar ao processo. Foi implementada uma parceria com a Secretaria Municipal de Apucarana para a concretização do projeto. Estabeleceu-se uma equipe pesquisadora e uma área de pesquisa para o estudo do tema. Foi organizado um grupo de estudos, o qual contou com a participação da pesquisadora e das professoras do Ensino Fundamental do 
município. Foram realizadas reuniões com os professores do município, e com base nos temas trabalhados em sala de aula se definiu os principais pontos de pesquisa para o Atlas de Apucarana. Esses professores integraram a pesquisa investigando a história do município.

Todo o processo de idealização do Atlas de Apucarana foi implementado em etapas, ao longo das quais os professores envolvidos no projeto faziam constantes leituras sobre o tema. Também foi desenvolvida uma pesquisa de prática educativa, na qual os idealizadores do projeto iam até os alunos com as páginas do atlas para estudar a repercussão do material junto a eles. Por fim, contou com oficinas de formação continuada para os professores do município. Essa experiência se mostrou frutífera, sobretudo por agregar a elaboração de recurso didático e o desenvolvimento de processos formativos, compreendidos como formação continuada de professores e professoras.

\section{Atlas Municipal de Sorocaba - SP}

O principal objetivo do trabalho que envolveu o município de Sorocaba foi a proposta de uma metodologia para a elaboração de um atlas escolar para o conhecimento do próprio local de estudo. Já na capa do atlas são demonstrados os limites do município, representando as feições e características do relevo local (Figura 3).

Figura 3 - Capa do Atlas municipal de Sorocaba - SP

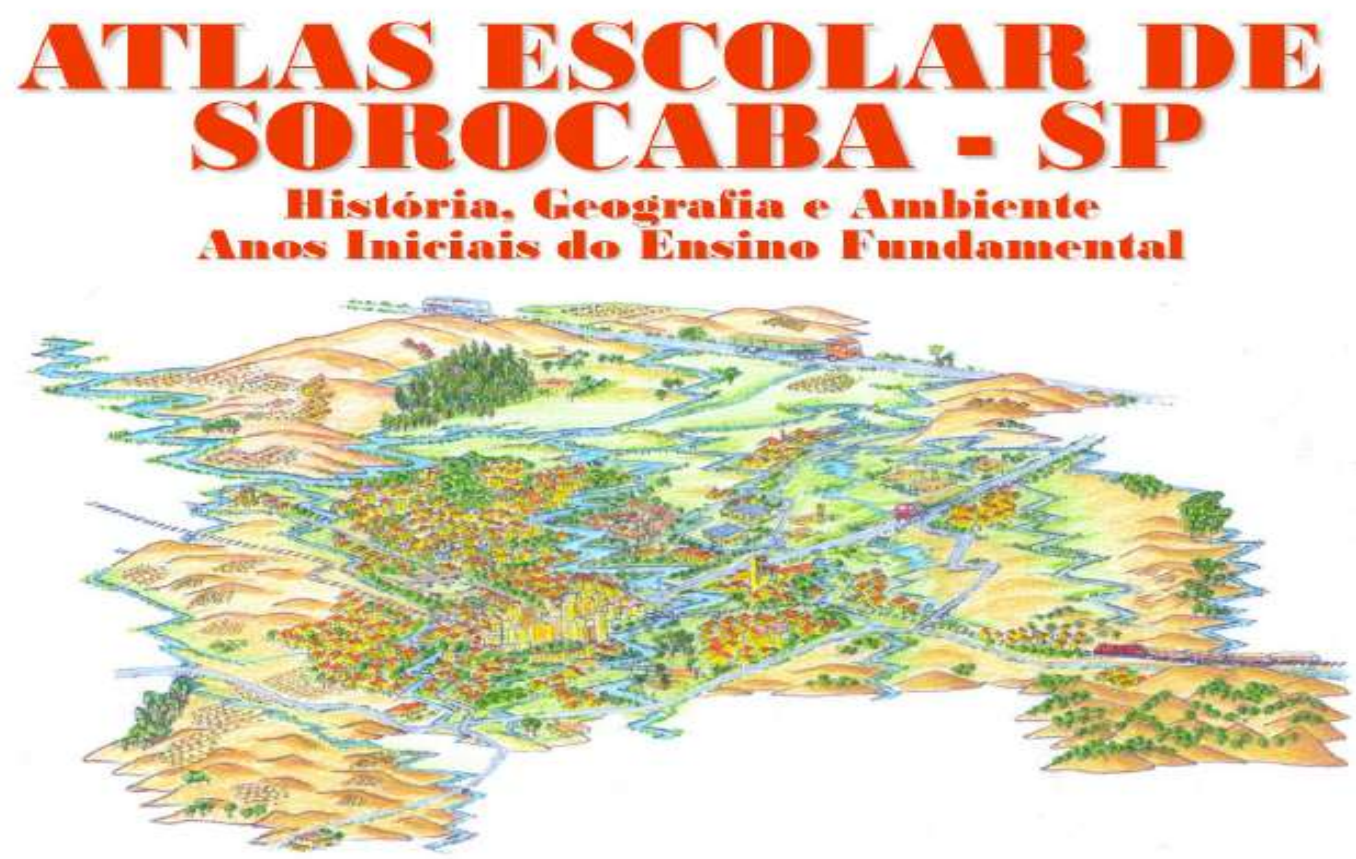

ELIZABETH DE SOUZA MACHADO-HESS

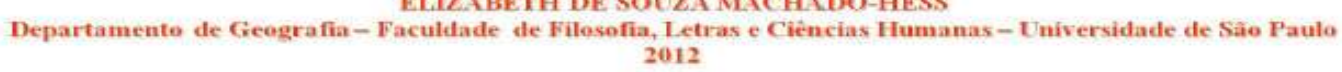

Fonte: Machado-Hess (2012a). 
Esse atlas teve como objetivo aplicar e avaliar a metodologia de construção do atlas municipal, mediante a implantação de um protótipo para os alunos do município de Sorocaba, bem como avaliar a adequação do protótipo ao trabalho em sala de aula.

O Atlas de Sorocaba contou em sua proposta com pranchas temáticas que abordaram os principais aspectos geográficos do município: político, relevo, hidrografia, geologia, recursos minerais, vegetação, clima, área urbana, área rural, uso da terra, cobertura do solo, população, indústria, rede viária, divisão da cidade, saúde, educação, saneamento básico, turismo etc., além de aspectos que envolvem a história de Sorocaba.

$\mathrm{Na}$ imagem da Figura 4, a autora do Atlas de Sorocaba tenta representar por meio de uma imagem e com elementos cotidianos, como a casca de uma fruta, as possibilidades de representação da realidade espacial, demonstrando as distorções que ocorrem ao transpor o globo para uma realidade plana.

Figura 4 - Imagem apresentada no Atlas de Sorocaba - SP demonstrando a representação da realidade espacial

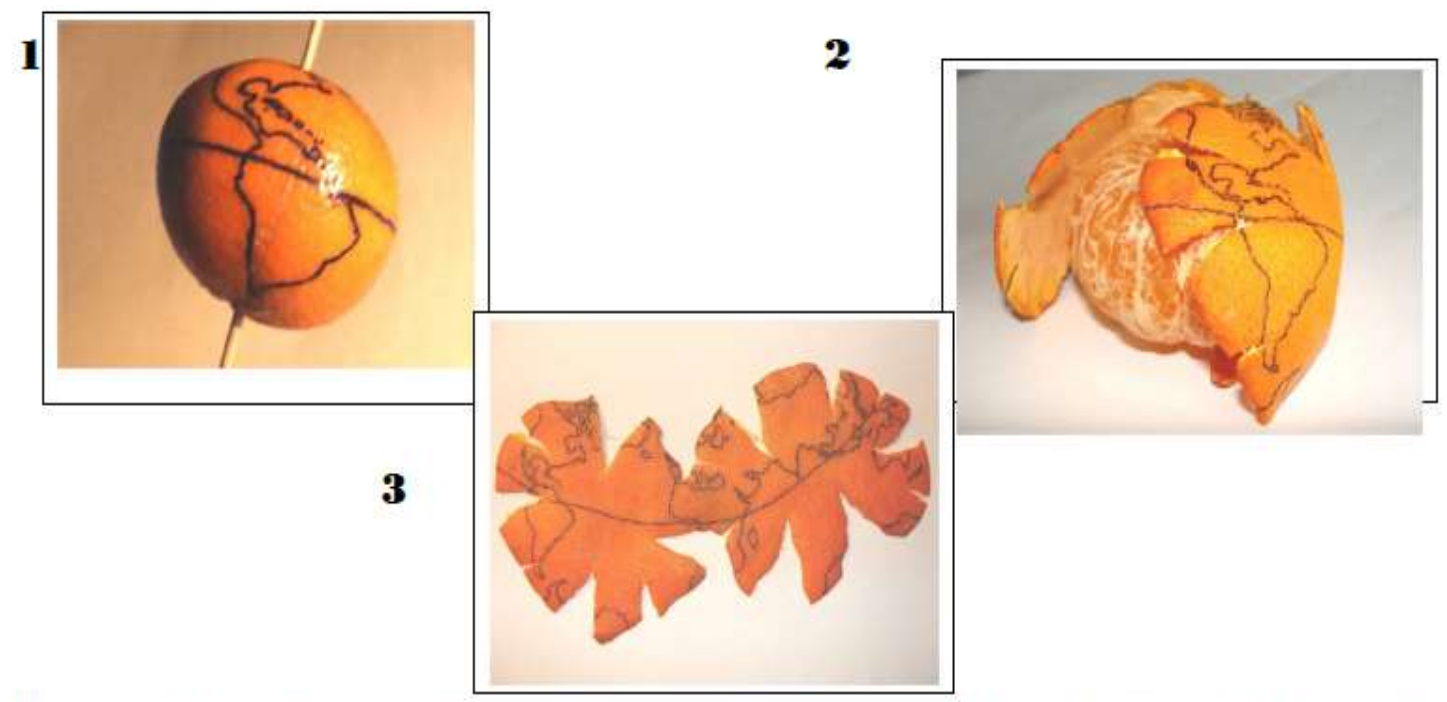

Representação dos continentes na casca de uma mexerica. Planificação da casca revelando as distorções ocorridas no processo.

Fonte: Machado-Hess (2012a).

Cada tema escolhido para compor o atlas ocupou duas páginas, com fonte Arial 12 , espaçamento simples entre linhas, contando principalmente com figuras, fotos, desenhos, croquis, infográficos e gráficos. A escala dos mapas utilizados foi de 1:150.000 e 1:80.000. Após a elaboração do protótipo do atlas, o processo teve continuidade por meio de aplicação e avaliação em sala de aula, buscando investigar a relação deste recurso didático com o fazer pedagógico concreto. O atlas de Sorocaba contou com 136 páginas. 


\section{Atlas Municipal de Restinga Sêca - RS}

Este trabalho reforça que o conhecimento de conceitos locais ajuda de uma forma significativa no conhecimento da identidade do aluno, quando seu município ganha importância social. Houve conversas exploratórias com professores e supervisores, bem como visitas às escolas para dimensionar a habilidade dos alunos com a iniciação cartográfica e sua relação com a representação em mapas. Priorizou um modelo de atlas municipal eletrônico, apostando no perfil tecnológico para o Ensino Fundamental. Cirolini (2014) afirma que a pesquisa procurou avaliar os efeitos da inclusão de tecnologias digitais nas escolas, focalizando sua aplicação no ensino de Geografia e Cartografia no meio rural do município de Restinga Sêca-RS. Ao longo da dissertação de Cirolini (2014) são apresentadas muitas figuras que ilustram a dinâmica eletrônica do atlas de Restinga Sêca, como na imagem a seguir (figura 5).

Figura 5 - Demonstração da localização do município de Restinga Sêca

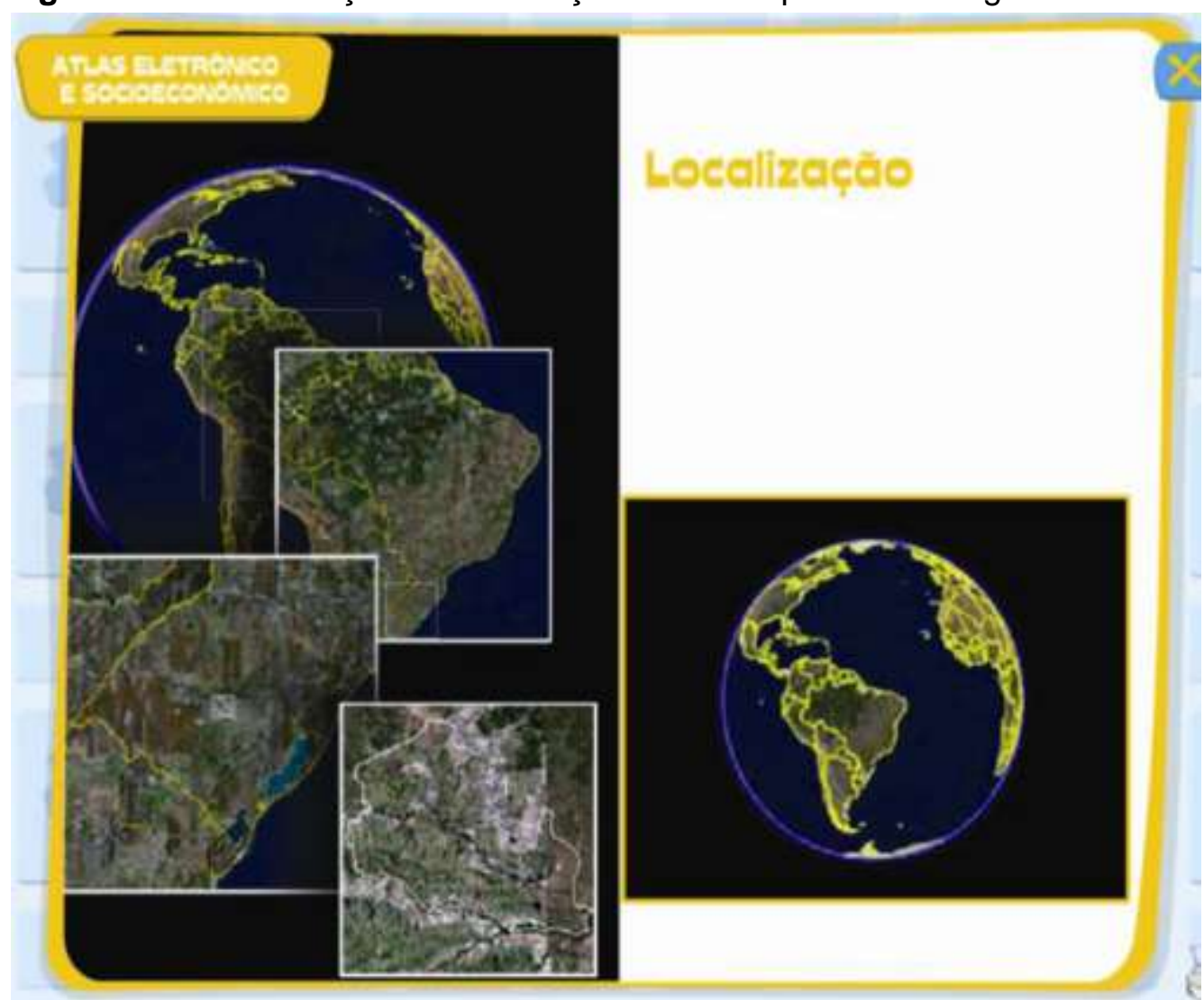

Fonte: Cirolini (2014).

No processo deste atlas foram envolvidos alunos do 6ํano de quatro escolas da área rural do município, com ênfase nos estudos da cartografia básica e temática, objetivando principalmente sua relação com o estudo da localidade. Após a finalização do projeto foi 
feita uma pesquisa com estes alunos e verificou-se que aqueles que utilizavam o atlas municipal nas aulas apresentaram menos dificuldades em relação ao desenvolvimento de atividades relacionadas com a Cartografia. A proposta objetivava construir a ideia de um "aluno mapeador".

Foram utilizadas abordagens gráficas e cartográficas, bem como temas bastante próximos da realidade local, com o fito de reforçar a identidade dos alunos com a sua espacialidade imediata.

\section{Atlas Municipal de Sena Madureira - AC}

Este projeto foi pensado pela doutoranda Miriam Aparecida Bueno em tese de doutorado, e por duas bolsistas de Iniciação Científica (PIBIC), do curso de Licenciatura em Geografia (UFAC), levando em consideração o quarto município mais populoso do Estado do Acre. Conforme Bueno (2008, p. 44), "Sena Madureira é um dos 22 municípios que compõem o estado do Acre, está situado na Microrregião de Sena Madureira, faz parte da bacia do Rio Laco, afluente do Purus, e ocupa a categoria de maior município de sua microrregião".

Seguiu a linha de pesquisa dos atlas escolares municipais elaborados no vale do Jequitinhonha. A formatação das páginas é de $210 \times 297$ milímetros, formato A4, a maior parte delas em preto e branco. As representações gráficas ficam na página direita e os textos na página esquerda. Os mapas do município de Sena Madureira têm escala de 1:1.500.000, onde cada centímetro, no mapa corresponde a 15 quilômetros na superfície do terreno; as plantas dos bairros apresentam escala maior, variando entre 1:5.000 e 1:10.000. Conforme as considerações de Bueno (2008, p. 49):

A seleção dos temas para as pranchas seguiu o formato original dos atlas de Le Sann (1997), que partia da análise do currículo do Ensino Fundamental, porém atendendo à ideia de regionalização. Nesse sentido, outros temas, como a biodiversidade no município, a situação fundiária e a navegabilidade no município, foram inseridos no atlas de Sena Madureira.

O público de destino do Atlas de Sena Madureira - AC foi o $2^{\circ}$ ciclo do Ensino Fundamental da região e logrou trazer para o estudo do município um forte traço da localidade onde os estudantes residem. 


\section{A UTILIZAÇÃO DO ATLAS ESCOLAR NA CONCEPÇÃO DOS PROFESSORES DE CANGUÇU}

Buscando compreender a perspectiva profissional sobre um possível atlas municipal e sua utilização, foram realizadas entrevistas com professoras que atuam no município de Canguçu - RS. As entrevistas ocorreram em dias alternados com oito docentes, das quais cinco ministram aulas de Geografia. Destas professoras, duas trabalham atualmente com turmas de $4^{\circ}$ ano do Ensino Fundamental. Cabe destacar que todas as entrevistadas, em algum momento de sua carreira profissional, atuaram com o $4^{\circ}$ ou $5^{\circ}$ ano e lecionaram conteúdos relacionados ao conhecimento sobre o município de Canguçu. As entrevistas foram realizadas em quatro escolas da zona urbana, sendo três escolas municipais e uma estadual. Duas das professoras entrevistadas trabalham em uma escola da zona rural de Canguçu.

Com as entrevistas buscou-se conhecer a realidade das escolas visitadas no município, reunir sugestões para uma possível elaboração de um atlas geográfico de Canguçu, verificar a importância didática do uso de atlas como recurso didático e relatar as formas como as professoras usam seus recursos didáticos, entre eles o atlas do IBGE, fornecido pelo Instituto às escolas, sendo utilizado por algumas das professoras.

A primeira pergunta que compôs a entrevista abordou o uso do atlas: "Você utiliza o atlas escolar geográfico (comprado pelos alunos ou fornecido pela escola) em suas aulas? Se utiliza algum atlas, com que frequência?". As informações obtidas com este questionamento foram bastante variadas, pois estão relacionadas com o contexto escolar e a maneira particular de cada professora atuar em sala de aula. Os dados referentes a esta pergunta estão apresentados no quadro a seguir (Quadro 1). Dentre os dados relatados, destaca-se um trecho da entrevistada o 2, quando a mesma afirma que:

Até o $4^{\circ}$ ou $5^{\circ}$ ano existe uma deficiência na questão de trabalhar o
conteúdo geográfico, é muito raro ver alunos do $1^{\circ}, 2^{\circ}$ e $3^{\circ}$ ano do ensino
fundamental conhecendo a Geografia, sendo que os professores dos anos
iniciais, que não tem uma formação especifica, trazem apenas noções de
português e matemática para seus alunos, esquecendo outros conteúdos
que são muito importantes, como é o caso da Geografia.

A entrevistada ratifica a lacuna do conhecimento geográfico na formação inicial dos profissionais que atuam no nível fundamental, dimensionando os impactos na aprendizagem dos alunos. 
Quadro 1 - Quadro de dados referente às respostas das professoras quanto à utilização do atlas escolar geográfico

\begin{tabular}{|c|c|c|c|}
\hline Entrevistada & $\begin{array}{l}\text { Formação } \\
\text { Inicial }\end{array}$ & $\begin{array}{l}\text { Área de } \\
\text { Atuação }\end{array}$ & Uso e frequência do atlas escolar nas aulas \\
\hline № 1 & Geografia & Geografia & $\begin{array}{l}\text { Sim, utiliza bastante, principalmente nas aulas } \\
\text { compostas por conteúdos de geografia física, neste } \\
\text { caso utiliza o atlas escolar geográfico do IBGE, pois a } \\
\text { escola possui este material. Não é possível, com } \\
\text { esse atlas, tematizar os aspectos do espaço local, } \\
\text { pois ele apresenta uma proposta genérica dos } \\
\text { conteúdos. }\end{array}$ \\
\hline № 2 & Geografia & Geografia & $\begin{array}{l}\text { Respondeu que utiliza o atlas escolar, aquele atlas } \\
\text { convencional e geral comprado por alunos em } \\
\text { livrarias ou papelarias da cidade de Canguçu. } \\
\text { Menciona que algumas escolas do munićpio } \\
\text { possuem alguns destes atlas em suas bibliotecas. } \\
\text { Utiliza esses atlas principalmente na introdução dos } \\
\text { conteúdos geográficos. }\end{array}$ \\
\hline № 3 & Letras & $\begin{array}{l}4^{\circ} \text { ano / Ensino } \\
\text { Fundamental }\end{array}$ & $\begin{array}{l}\text { Destaca que existe uma grande precariedade com } \\
\text { relação à falta de mapas e de outros recursos para } \\
\text { se trabalhar, em sala de aula, os aspectos tanto do } \\
\text { meio rural quanto do meio urbano, sendo que o atlas } \\
\text { é um dos recursos cuja ausência é mais sentida em } \\
\text { suas aulas. A escola não possui o atlas do IBGE. }\end{array}$ \\
\hline № 4 & História & $\begin{array}{l}\text { História/ } \\
\text { Geografia }\end{array}$ & $\begin{array}{l}\text { Utiliza raramente, pois o considera apenas um } \\
\text { complemento, utilizando principalmente o livro } \\
\text { didático. Segundo ela, o livro apresenta muitos } \\
\text { mapas temáticos que são interessantes de serem } \\
\text { trabalhados. }\end{array}$ \\
\hline № 5 & Geografia & Geografia & $\begin{array}{l}\text { Utiliza o atlas escolar com bastante frequência, pois } \\
\text { o considera uma ferramenta fundamental, aponta: } \\
\text { "Assim como se usa o dicionário para o português, se } \\
\text { usa o atlas para a Geografia". }\end{array}$ \\
\hline № 6 & História & Geografia & $\begin{array}{l}\text { Afirma que usa o atlas com frequência, } \\
\text { principalmente para a apresentação de conteúdos } \\
\text { novos, relata também que em algumas turmas chega } \\
\text { a utilizar o atlas diariamente. Possui acesso somente } \\
\text { aos atlas do IBGE. }\end{array}$ \\
\hline № 7 & $\begin{array}{l}\text { Estudos } \\
\text { Sociais }\end{array}$ & $\begin{array}{l}4^{\circ} \text { e } 5^{\circ} \text { ano / } \\
\text { Ensino } \\
\text { Fundamental }\end{array}$ & $\begin{array}{l}\text { Em algumas aulas utiliza o atlas escolar, sempre de } \\
\text { acordo com o conteúdo trabalhado, relata que nos } \\
\text { demais dias o seu atlas fica exposto na sala de aula, } \\
\text { caso os alunos queiram consultar o mesmo. }\end{array}$ \\
\hline № 8 & Sociologia & Geografia & $\begin{array}{l}\text { Utiliza o atlas escolar em quase todas as aulas, mas } \\
\text { ressalta que muitas escolas não possuem o material. }\end{array}$ \\
\hline
\end{tabular}

Fonte: organização dos autores (2019).

A segunda questão indagou sobre o interesse discente durante o manuseio do atlas: "De acordo com sua experiência o que mais desperta o interesse do aluno quando ele utiliza um atlas escolar geográfico?" Nesta questão as respostas foram quase que unânimes. Todas as professoras entrevistadas afirmaram que os alunos gostam do atlas, pois se sentem atraídos por ele. Manifestam uma grande curiosidade em saber onde se localizam no mapa, onde fica determinado país ou determinado local, visto que os atlas convencionais trazem mapas mais gerais, apenas do país e do estado, onde os alunos têm maior dificuldade de localizarem seu município ou seu local de moradia. Ressaltam que a 
realidade fica mais nítida e visível, sendo o atlas uma ferramenta de pesquisa sobre diversos temas, relatando que quando o aluno tem seu contato inicial com um material cartográfico, sente interesse em decifrar e compreender os mapas. A professora $n^{0} 4$ ressalta que muitos têm interesse em conhecer a bandeira de determinados países.

A terceira e última questão explorou a composição de um eventual atlas sobre o contexto municipal: "Em sua opinião, que informações seriam relevantes em um atlas sobre o município de Canguçu?"

Tal questionamento revelou-se extremamente importante, sendo que as entrevistadas relataram um grande déficit nessa área. São raros os materiais que possibilitam trabalhar com os conteúdos do município de Canguçu e, além disso, encontram-se dispersos. Elas consideram que seria muito interessante que um atlas escolar geográfico de Canguçu fosse elaborado e destacaram que seriam importantes as informações com relação aos subdistritos, bairros, população, uso do solo, nomes de ruas, produtos cultivados e produção econômica de cada subdistrito, número de propriedades em cada subdistrito, aspectos físicos e econômicos, localização no Estado do Rio Grande do Sul, formação histórica do município e divisão territorial, assim como diversas outras informações.

As professoras que trabalharam ou trabalham com o $4^{\circ}$ ano explicam que, atualmente, usam com seus alunos o livro: "Nos Caminhos de Canguçu", escrito e organizado por Bosenbecker (2013). Segundo as professoras esse material é praticamente o único disponível sobre o contexto municipal, além de alguns mapas desatualizados, porém apresenta somente o essencial. Para os alunos conhecerem todos os demais aspectos geográficos de seu município seriam necessários dados mais aprofundados e específicos, além de serem mais bem dimensionados didaticamente.

\section{CONSIDERAÇÕES FINAIS}

A partir das concepções apresentadas pode-se ratificar a compreensão de que o atlas geográfico municipal é uma base relevante para o ensino de Geografia no nível fundamental. Por meio dele, os estudantes podem conhecer melhor seu município, e assim se familiarizar com a disciplina de Geografia desde os primeiros anos do Ensino Fundamental.

Por meio da realização das entrevistas foi possível obter uma dimensão das diferentes concepções profissionais sobre o atlas geográfico e seu uso em sala de aula. As propostas de atlas analisados contaram com o uso de pesquisas participantes, nas quais os professores da rede de ensino e os alunos, público alvo dos atlas, expuseram suas opiniões e sugestões frente a temas que foram inseridos nas propostas. Também promoveram 
atividades de integração com a comunidade e utilizaram, como embasamento teórico e prático, pesquisas de outras propostas já concretizadas.

A realidade apresentada pelas entrevistas, atrelada às propostas de atlas de outros municípios brasileiros, revelou diferentes realidades pedagógicas, distintas metodologias e formas de ensinar, que junto das sugestões de temáticas sobre o município de Canguçu, trazem à tona aspectos que moldam possíveis abordagens em um atlas escolar do município de Canguçu.

A elaboração de um atlas geográfico municipal, da mesma forma como foram propostos em vários outros municípios do Brasil, tais como: Restinga Sêca - RS, Sumaré SP, Apucarana - PR, Sorocaba - SP e Sena Madureira - AC, possibilita que os alunos tenham um interesse maior pelos mapas e os conhecimentos gerais que envolvem o seu contexto. Além disso, constitui um apoio fundamental para os professores trabalharem temas da Geografia, pois as informações focadas no município conduzem a criança à análise crítica da realidade local. Cabe destacar que este artigo não busca avaliar as propostas dos atlas aqui apresentados, mas trazer ao leitor as diversas possibilidades de se constituir essa ferramenta didática, bem como observar suas diferentes abordagens em diferentes municípios brasileiros.

Com a pesquisa observou-se que as propostas de elaboração e consequente disponibilização de atlas em alguns municípios brasileiros foi algo promissor para o ensino de Geografia. Ao mesmo tempo, os processos de elaboração participativa revelaram perspectivas positivas como estratégia de formação continuada de professores, instigando a adoção dessa metodologia em projetos a serem executados com a mesma finalidade. Ao participarem ativamente da elaboração do atlas, professores e professoras aprofundam seus conhecimentos em múltiplas dimensões da ciência geográfica, de forma concomitante à demanda pedagógica manifestada pelo seu contexto de atuação.

Por meio das entrevistas, ainda que componham uma amostra limitada, percebeu-se que o atlas geográfico geral para o Brasil (adquirido por alunos ou fornecido pelas escolas) é utilizado nas aulas de Geografia de Canguçu, em algumas escolas. Porém segundo as professoras entrevistadas, os atlas convencionais se equiparam a muitos livros didáticos, por conterem as mesmas informações e ignorarem o espaço local.

As experiências das professoras entrevistadas contribuíram para o esclarecimento do modo como trabalham com o atlas escolar geográfico em sala de aula, identificando, também, a inexistência de conteúdos geográficos do município. Em consequência, permitem que sejam propostas soluções para a elaboração de um atlas com esse escopo, baseado em boas experiências, como os casos mencionados. O uso desse material didático representa uma ferramenta frutífera no processo educativo. 
Observa-se que, com um material escasso, muitos professores não têm como aprofundar o estudo do município e acabam adentrando de modo superficial em alguns temas. Isto faz com que os alunos cheguem no $5^{\circ}$ ou $6^{\circ}$ ano apresentando maior dificuldade para compreender a Geografia, o que se refletirá, acredita-se, em problemas futuros. Se o aluno não é capaz de entender o seu município, ele terá dificuldades para entender dimensões que extrapolam o contexto local, em direção ao global. Com a elaboração de um atlas geográfico municipal, os professores teriam um material mais denso e elaborado para aprofundar os estudos do município.

Os cinco atlas analisados demonstram uma abordagem geográfica comprometida com as informações de caráter local, cuja característica simples, embora não simplista, permite que sejam adotados como exemplos para a elaboração de novos atlas. O perfil coletivo que permeou a construção de alguns também merece ser enfatizado, ensejando até mesmo projetos de elaboração em sala de aula, materializando a construção do conhecimento em meio a processos de formação da autonomia.

$\mathrm{O}$ atlas de Canguçu poderia abordar temas e possíveis mapas temáticos sobre abordagens geográficas como: relevo, hidrografia, clima, questões ambientais, características urbanas e rurais, atividades econômicas e questões étnicas e históricas, tendo a apresentação de imagens e mapas que demonstrassem ao público leitor as características ilustradas do município tematizado.

Portanto, conclui-se que a elaboração participativa de um atlas geográfico do município de Canguçu representa uma proposta promissora, articulando experiências de outros municípios e saberes profissionais de pessoas que atuam no contexto das escolas localizadas no município, contribuindo para a sua qualificação.

\section{REFERÊNCIAS}

AGUIAR, L. M. B. O lugar e o mapa. Cadernos Cedes, Campinas, v. 23, n. 60, p. 139-148, 2003.

ALMEIDA, R. D. Atlas Municipais elaborados por professores: a experiência conjunta de Limeira, Rio Claro e Ipeúna. Cadernos Cedes, Campinas, v. 23, n. 60, p. 149-168, 2003.

BOSENBECKER, L. B. Nos caminhos de Canguçu. [S. I.]: Impressão livre, 2013.

BUENO, M. A. Atlas escolares municipais e a possibilidade de formação continuada de professores: um estudo de caso em Sena Madureira/AC. 2008. Tese (Doutorado em Ciências) - Instituto de Geociências, Universidade Estadual de Campinas, Campinas, 2008.

CIROLINI, A. A inclusão de tecnologias digitais nas escolas do meio rural de Restinga

Sêca, RS: o atlas eletrônico e escolar nas perspectivas dos processos de ensino aprendizagem. 2014. Tese (Doutorado em Geografia) - Instituto de Geociências, Universidade Federal do Rio Grande do Sul, Porto Alegre, 2014.

FARIA, M. C. C. A pesquisa participante na elaboração de atlas municipal escolar: a experiência do atlas de Apucarana-PR. 2015. Tese (Doutorado em Geografia) - Instituto de 
Geociências e Ciências Exatas, Universidade Estadual Paulista Júlio de Mesquita Filho, Campus de Rio Claro, Rio Claro, 2015.

FRANÇA JUNIOR, P.; ZUCCHI, V. P. A construção do atlas municipal de Cambira/PR: para o ensino e a aprendizagem geográfica do lugar. Geografia Ensino \& Pesquisa, Santa Maria, v. 17, n. 1, p. 161-171, 2013.

GIL, A. C. Como elaborar projetos de pesquisa. São Paulo: Atlas, 2002.

IBGE. Censo. 2010. Disponível em: www.ibge.gov.br. Acesso em: 12 ago. 2019.

IBGE. Portal do Governo Federal. Disponível em: http://www.cidades.ibge.gov.br/ Acesso em: 18 ago. 2018.

LIMA, A. S. Atlas escolar De Sumaré (SP): os saberes produzidos nas práticas pedagógicas cotidianas de uma professora do $4^{\circ}$ ano do ensino fundamental. 2013. Dissertação (Mestrado em Geografia) - Instituto de Geociências e Ciências Exatas, Universidade Estadual Paulista Júlio de Mesquita Filho, Campus de Rio Claro, Rio Claro, 2013.

MACHADO-HESS, E. S. Atlas escolar de Sorocaba - SP: história, geografia e ambiente (anos iniciais do ensino fundamental). São Paulo: [s. n.], 2012a.

MACHADO-HESS, E. S. Uma proposta metodológica para a elaboração de atlas geográficos escolares para os anos iniciais do ensino fundamental: o exemplo do munícipio de Sorocaba/SP. 2012. Tese (Doutorado em Geografia Humana) - Faculdade de Filosofia, Letras e Geografia Humana, Universidade de São Paulo, São Paulo, 2012b.

MARTINELLI, M. Um atlas geográfico escolar para o ensino-aprendizagem da realidade natural e social. Portal da Cartografia, Londrina, v. 1, n. 1, p. 21-34, 2008.

MARTINELLI, M.; FERREIRA, G. M. L. A cartografia para os atlas geográficos para crianças. In: COLÓQUIO CARTOGRAFIA PARA CRIANÇAS, 1995, Rio Claro. Anais [...]. Rio Claro: UNESP/USP, 1995. p. 37-40.

Recebido: agosto de 2019. Aceito: janeiro de 2020. 